\title{
PAIN ATTENUATION WITH LOW LEVEL LASER THERAPY ON PERIARTHRITIS SCAPULOHUMERALIS
}

\author{
Toshiyuki Kobayashi ${ }^{1}$, Yoshirou Musha ${ }^{1}$, Kazuhiro Mizutani ${ }^{1}$, Takashi Harada ${ }^{2}$ and Toshio Ohshiro ${ }^{3}$
}

Departments of 1: Second Orthopedic Surgery and 2: Physical Medicine and Rehabilitation, School of Medicine, Toho University, Tokyo; and 3: Japan Medical Laser Laboratory, Tokyo, Japan

\begin{abstract}
The cascade system of biological integrity with an emphasis on low level laser therapy (LLLT) is poorly understood. A clinical study was made to assess pain attenuation with LLLT in connection with serum prostaglandin (PG)E2 levels. Seventy six women with periarthritis scapulohumeralis, mean age of 61.4 years, were exposed to a diode semiconductor laser unit with an output power of one watt and wavelength of $830 \mathrm{~nm}$. Irradiation was administered for 3 minutes daily or on alternate days, for a total of 10 times. The therapy proved effective in 64 cases or $84.2 \%$. There was no significant correlation between age and length of condition and the effectiveness of LLLT. The relevant pain-scoring system with a visual analog scale (VAS), 30.0 2.0 after irradiation in the clinically affected group, was significantly lower than $80.3 \pm 2.5$ before irradiation in the same group and also lower than $64.2 \pm 6.3$ after irradiation in the group unaffected by this therapy. In the affected group PGE2 levels were $5.4 \pm 0.3$ after irradiation, which were significantly lower than $7.2 \pm 0.5$ before irradiation. In the unaffected group, however, there was no significant difference between PGE2 levels before and after irradiation. Substantial change in PGE2 levels showed a significant difference by group. The result suggests that LLLT can often alleviate nociceptive pain associated with the decline of serum PGE2 levels.
\end{abstract}

Key words: Low level laser therapy, periarthritis scapulohumeralis, PGE2

\section{Introduction}

Although irradiation with low levels of laser energy(1) in clinical trials has been reported to offer a treatment alternative to the conventional analgesics and often debilitating pain with acceptable ease and safety, the mechanisms in detail whereby low level laser therapy (LLLT) modulates the articulating of anti-nociception remains obscure ${ }^{(2)}$. Out of the pro-inflammatory prostanoids ${ }^{(3)}$, prostaglandin (PG)E2 plays an important role in the delineation of the nociception in the peripheral nervous system ${ }^{(3)}$ as well as in the spinal $\operatorname{cord}^{(4,5)}$.

The goal of this study is to clarify the clinical efficacy of LLLT in alleviating symptomatic pain of periarthritis scapulohumeralis particularly in connection

\footnotetext{
Addressee for Correspondence:

Toshiyuki Kobayashi MD,

Department of Second Orthopedic Surgery,

School of Medicine, Toho University, Tokyo,

2-17-6 Ohashi Meguro-ku,

Tokyo 153-8515, Japan

TEL:+81-3-3648-1251 FAX:+81-3-3468-0361
}

with serum levels of PGE2 ${ }^{(6-8)}$

\section{Material and Method}

The study sample were 76 female patients who received LLLT at our facility. Clinical pain assessment was made by the patients before and after laser irradiation. Age distribution ranged from 31 to 86 years old, the mean age being 61.4 years. The period of illness ranged from 3 days to 3 years with a mean of 7.6 months.

The diode semiconductor laser system used was Medilaser soft $1000^{\circledR}$ by Matsushita Electric Co., Ltd. This device has a continuous wavelength of $830 \mathrm{~nm}$. and an output power of $1 \mathrm{~W}$. The spot size is 1.538 $\mathrm{cm}^{2}$, giving an incident irradiance of $0.67 \mathrm{~W} / \mathrm{cm}^{2}$.

The irradiation time per trigger point was $15 \mathrm{sec}-$ onds with a total of 3 minutes per day, total radiant flux of $97.5 \mathrm{~J} / \mathrm{cm}^{2}$. Laser exposure was done either every day or every other day for a total of ten times.

Manuscript received: September 2006

Accepted for publication: Octorber 2006 
Table 1: Analgesic effects with laser irradiation are proved to be creditable at least $84.2 \%$.

Group

Numbers of patients (\%)

Mean age (years)

Morbid period (month)
Effective Ineffective

\begin{tabular}{|c|c|c|}
\hline $64(84.2 \%)$ & & $12(15.8 \%)$ \\
\hline & N.S. & \\
\hline $61.2 \pm 1.4$ & & $62.4 \pm 3.0$ \\
\hline & N.S. & 0 \\
\hline
\end{tabular}

Table 2: Typical VAS evaluation by group revealed a significant difference before and after laser exposure.

Group

$$
\begin{array}{cc}
\text { Effective } \\
n=64 & \text { Ineffective } \\
n=12
\end{array}
$$

Laser exposure

N.S.

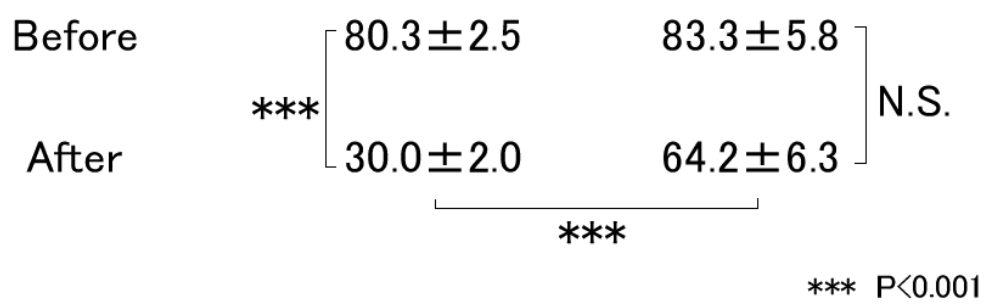

Table 3: Showing measurement of prostaglandin E2 levels $(\mathrm{pg} / \mathrm{ml})$ in the serum by the group with or without laser exposure.

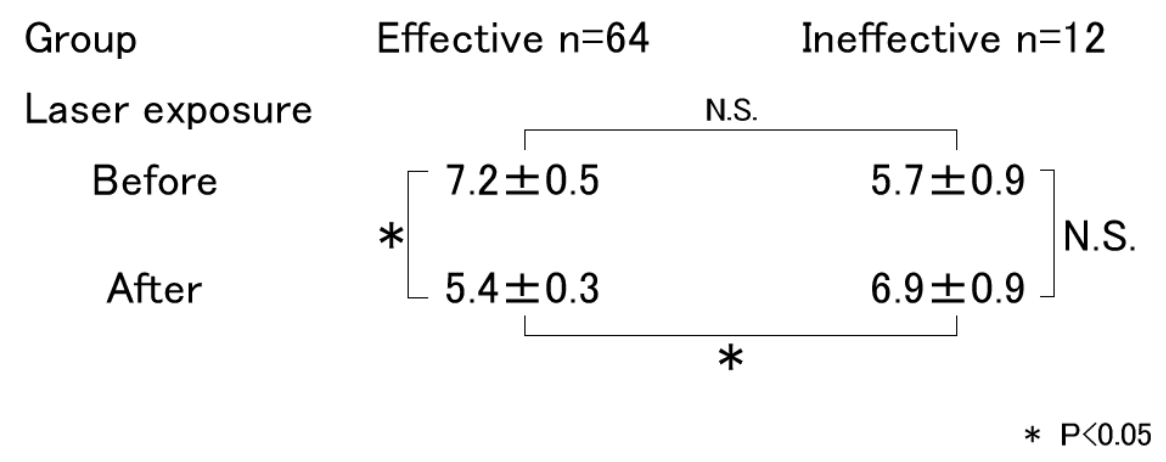


No other physical or analgesic or chemical medications were used during the treatment.

Items evaluated were the following: 1) Rating of the analgesic effect as effective or ineffective according to the patients' perception, 2) Scoring on an 11 point visual analog scale (VAS) with a line length of $100 \mathrm{~mm}$, and 3) Measurements of PGE2 levels in the serum were performed using the RIA-PEG method (ARC-950 $\gamma$ Counter ${ }^{\circledR}$, Aloka Co., Ltd.) with the standard set as normal below $4.4 \mathrm{pg} / \mathrm{ml}$.

Mean and standard deviation was calculated for the each of the parameters. Statistical analysis of the data was performed as a paired or non-paired Student's t-test. P values less than 0.05 were considered indicative of a significant difference.

\section{Results}

Pain attenuation was effective for 64 out of 76 patients or $84.2 \%$ (Table 1). No significant dif-ferences in mean age and length of illness were noted between those for whom the treatment was effective and those for whom it was ineffective. According to the result of a typical VAS evaluation, the mean score recorded after laser exposure was significantly lower than that recorded before laser exposure in the effective group, namely $30.0 \pm 2.0$ and $80.3 \pm 2.5$ respectively $(\mathrm{p}<0.001)$ (Table 2).

The mean VAS score 30.0 \pm 2.0 recorded after laser exposure in the effective group was also significantly lower than that of $64.2 \pm 6.3$ recorded after laser exposure in the ineffective group $(\mathrm{p}<0.001)$. As to the changes in VAS evaluation before and after laser exposure, significant differences were observed between the effective and ineffective group, which were $-50.3 \pm 2.6$ and $-19.2 \pm 2.9$ respectively.

According to the results of the PGE2 measurement, the score recorded after laser exposure was significantly lower than that recorded before laser exposure in the effective group $(\mathrm{p}<0.05)$, namely $5.4 \pm 0.3$ $\mathrm{pg} / \mathrm{ml}$ and $7.2 \pm 0.5 \mathrm{pg} / \mathrm{ml}$ respectively (Table 3 ). On the other hand, the reverse was not true in the ineffective group. As to the substantial change in PGE2 levels ( $\mathrm{pg} / \mathrm{ml})$ before and after laser exposure, significant differences were observed between the two groups $(\mathrm{p}<0.05)$, which were $-1.7 \pm 0.5$ and $1.2 \pm 0.8$ respectively. In order to calculate the rate of changes (\%) of PGE2, the serum levels before and after laser irradiation were compared between the two groups. The percent outcome in the effective group was significantly lower than that in the ineffective group, which were $-7.9 \pm 6.5 \%$ and $39.6 \pm 18.7 \%$ respectively $(p<0.05)$.

Linear regression analysis of the effective group demonstrated a negative correlation between the PGE2 levels before laser exposure and the values of PGE2 obtained by subtracting the levels after irradiation from the preirradiation values (Fig. 1).

Subdivision of the effective group allocation by the standard of PGE2 levels revealed no more than 22 out of 64 cases or $34.4 \%$ who were below the standard after laser irradiation (Fig. 2). That is to say, in the residual 42 cases or $65.6 \%$ of the effective group, PGE2 levels remained high even after laser exposure.

A breakdown of the 33 effective subgroup allocation with high PGE2 levels above the standard simultaneously before and after laser exposure demonstrated a significant decline, $8.8 \pm 0.6 \mathrm{pg} / \mathrm{ml}$ and $7.0 \pm 1.5 \mathrm{pg} / \mathrm{ml}$ respectively $(\mathrm{p}<0.01)$ (Table 4). Little evidence, however, was provided to confirm the same trend in those patients allocated to the ineffective subgroup.

\section{Discussion}

Periarthritis scapulohumeralis was first described by Dupley in 1872.(9) Thereafter, it was re-ported that adhesive capsulitis ${ }^{(10)}$ in the region of the articular capsule and the rotator cuff(11) could cause restricted mobility of the shoulder. ${ }^{(12)}$ Idiopathic chronic adhesive capsulitis ${ }^{(13)}$ is believed to comprise freezing, frozen and thawing phases of 3 to 4 months each.

None of the subjects in the present study demonstrated any involvement of the underlying in-trinsic etiological disorder ${ }^{(14)}$. That is why the condition in all of the patients could, therefore, be categorized taxonomically as periarthritis scapulohumeralis. Beneficial amelioration through LLLT is of great importance, (1) because it is efficacious for diverse clinical applications in pain relief, vasodilatation, accommodation to autonomic dysfunction and enhanced autoimmune activity.

Thermographic imaging of the back of patients irradiated with LLLT has been reported, indicating a dramatic increase in the local skin temperature which can be attributed to the increased regional blood delivery after LLLT.

Pain attenuation with LLLT could well be summarized as follows, whatever the laser system being used may be. Through the laser catalyzed reaction, inhibition of production and release of inflammatory mediators and neurotransmitters as well as their effects on receptors in response to peripheral noxious stimuli can be crucial. Subsequent inhibition of excitation of receptors and $\mathrm{A} \delta$ and $\mathrm{C}$ nociceptive fibers are probably involved. ${ }^{(2,15)}$ Activation of the descending pain control pathway can also be predicted. Consequently, a verifiable improvement of local acidosis with vasodilatation followed by destruction of the vicious circle 


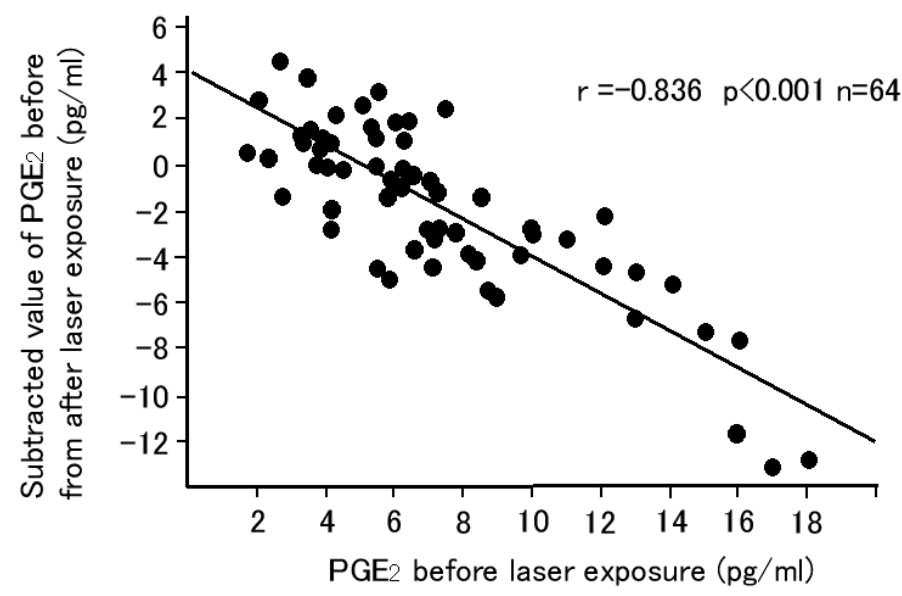

Fig. 1: Linear regression analysis of the effective group are illustrated significant correlation ship between the subtracted value of prostaglandin E2 before from after laser exposure and the prostaglandin E2 value before exposure.

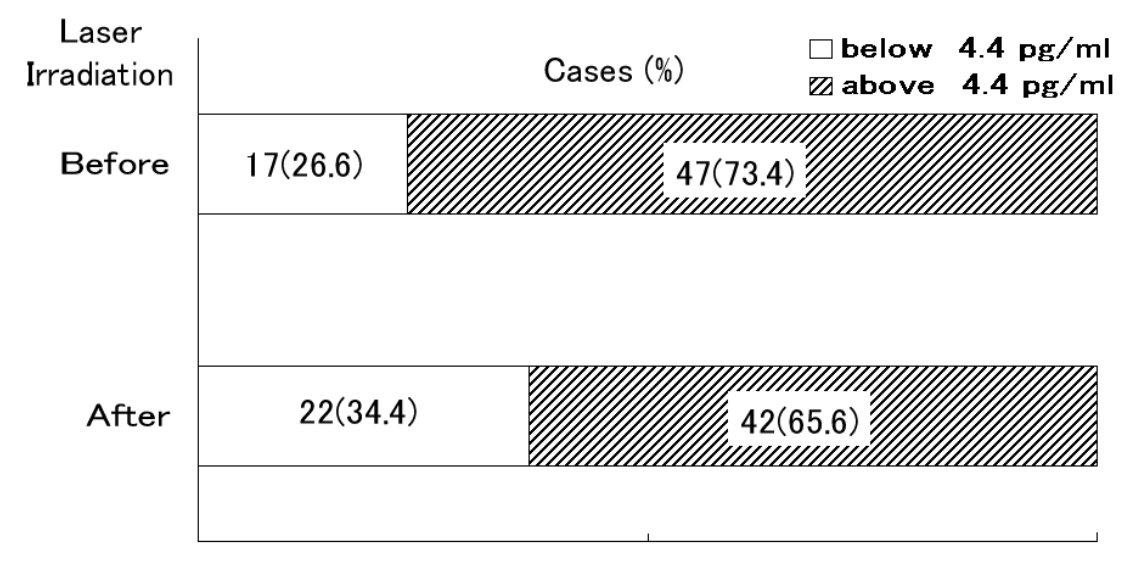

Fig. 2: According to the subdivision of all of the effective group allocation, little of drastic improvement of the cases above the standard of prostaglandin E2 levels were accounted by laser irradiation.

$\begin{array}{cc}\text { Group } & \text { Effective } \\ \mathrm{n}=33 & \mathrm{n}=7\end{array}$

Laser exposure

PGE2 levels $(\mathrm{pg} / \mathrm{ml})$

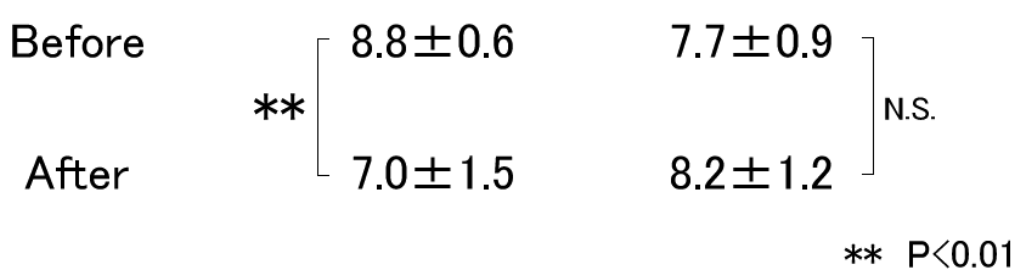

Table 4: The breakdown of effective group with high prostaglandin E2 levels concomitantly before and after laser irradiation are characterized by the significant decline. 
associated with pain may be established.

Enhancement of bradykinin ${ }^{(16)}$ by noxious stimuli leads to the production of $\mathrm{PGE} 2^{(17)}$, nitric oxide ${ }^{(18)}$ and neuropeptides. This process plays an important role in the occurrence of nociceptive pain ${ }^{(6)}$ as well as augmentation of sensitization. ${ }^{(19)}$ A statistical analysis was performed to investigate PGE2 levels which leads to the elicitation of painful responses. The inhibition of PGE2 induction is assumed to be a major element for pain relief, however, all patients are not created equal in this respect. In fact, no more than 22 cases or $34.4 \%$ out of the 64 affected cases had PGE2 levels under the standard $4.4 \mathrm{pg} / \mathrm{ml}$ even after laser irradiation.

Neuropeptides ${ }^{(7)}$ such as glutamic acid, substance $\mathrm{P}$ and calcitonin gene related peptides which are all produced at the dorsal root ganglion have been reported as being closely associated with cyclooxygenase 2 (COX2) activation, ${ }^{(20,21)}$ through which in turn subsequent $\mathrm{PGE} 2^{(6-8)}$ generation and $\mathrm{EP} 3^{(22)}$ subtype expression in the spinal cord ${ }^{(4,5)}$ are implicated in the maintenance of the pain state ${ }^{(8)}$ as well as in the occurrence of hyperalgesia(23) and allodynia. ${ }^{(24)}$ Neuropathic pain is usually resistant to analgesics and can be very difficult to treat. Adjunct enumerations are supposed to include complex regional pain syndrome, ${ }^{(25)}$ causalgia, diabetic polyneuropathy and postherpetic neuralgia. (26)

The pain attenuation mechanism thus involves a number of complex and integrated entities which remain to be explained, besides the biological operation of the expression of PGE2 in the serum. That is the reason why no less than two-thirds of the affected group demonstrated PGE2 levels above the standard level, even after LLLT.

The regressive analysis of the affected group, however, made it possible to predict that the higher the PGE2 levels before laser exposure, the more susceptible to LLLT would the patient be. In the discrete affected 33 patients with high PGE2 levels before as well as even after laser irradiation, laser exposure accounted for a significant decline in prostaglandin E2 concentration in the serum.

LLLT may, therefore, inhibit the arachidonic acid cascade in tissue leading to decreased PGE2 production in endothelial cells. This phenomenon affects nociceptive modulation by various chemical transmitters as well as pro-inflammatory cytokines. $(6,27,28)$ A local increase in blood flow improves the stagnant anoxia and promotes the release and removal of painrelated substances. Accordingly, excitation of mechanical and polymodal nociceptors appeared to be controlled.

\section{Conclusion}

Low level laser therapy using a unit with an output power of $1 \mathrm{~W}$ effectively attenuated omalgia in $84.2 \%$ of patients with periarthritis scapulohumeralis and significantly improved their VAS scores. This suggests the potential for reducing PGE2 expression in the serum leading to the inhibition of sensitization in nociceptive pain.

\section{References}

1: Beckerman H, de Bie RA, Bouter LM, De Cuyper HJ, Oostendorp RA (1992): The efficacy of laser therapy for muscloskeletal and skin disorders. Phys Ther, 72:483-91.

2: Sato T, Kawatani M, Takeshige C, Matsumoto I (1994): Ga-Al-As laser irradiation inhibits neuronal activity associated with inflammation. Acupunct Electrother Res, 19:141-51.

3: Horiguchi S, Ueno R, Hyodo M, Hayashi O (1996): Alternations in nociception after in-tracisternal administration of prostaglandin D2, E2 or F2 $\alpha$ to conscious mice. Pain, 67:345-354.

4: Ibuki T, Matsumura K, Yamazaki Y, Nozaki T, Tanaka Y, Kobayashi S (2003): Cyclooxy-genase-2 is induced in the endothelial cells throughout the central nervous system during carrageenaninduced hind paw inflammation; its possible role in hyperalgesia. J Neuro-chem. ,86:318-28.

5: Pitcher GM, Henry JL (1999): Mediation and modulation by eicosanoids of responses of spinal dorsal horn neurons to glutamate and substance $\mathrm{P}$ receptor agonists: results with in-domethacin in the rat in vivo. Neuroscience, 93:1109-21.

6: Oka T, Auo S, Hori T (1997): Intracerebroventicular injection of prostaglandin E2 induced thermal hyperalgesia in rats. Brain Res. pp 663:287-92.

7: Vanegas H, Schaible HG (2001): Prostaglandins and cyclooxygenases [correction of cy-cloxygenases] in the spinal cord. Prog Neurobiol, 64:327-63.

8: Yang LC, Marsala M, Yaksh TL (1996): Characterization of time course of spinal amino acids, citrulline and PGE2 release after carrageenan/kaolin-induced knee joint inflammation: a chronic microdialysis study. Pain, 67:345-54.

9: Duplay (1945): De la periarthrite scapulo-humerale et des raideurs de lepaule qui en sont sa consequence. Arch. Gem. De Medicine, 2:513-42.

10: Neviaser JS(1945): Adhesive capsulitis of the shoulder. J Bone Joint Surg, 27:211-22.

11: Nobuhara K, Ikeda H (1987): Rotator interval 
lesion. Clin Orthop Relat Res, 223:44-50.

12: Nicholson GG (1985): The effects of passive joint mobilization on pain and hypomobility associated with adhesive capsulitis of the shoulder. Orthop Sports Phy Ther, 6:238-46.

13: Rowe CR, Leffert RD (1988): Idiopathic chronic adhesive capsulitis "Frozen shoulder". In The shoulder. Rowe CR editor. New York, Churchill Linvingstone. pp 155-163.

14: Zuckerman JD, Cuomo Frances (1993): Frozen shoulder. The Shoulder; A balance of mobility and stability. American Academy of Orthopaedic surgery. pp 253-68.

15: Tsuchiya K, Kawatani M, Takeshige C, Sato T, Matsumoto I (1993): Diode laser irradiation selectively diminishes slow component of axonal volleys to dorsal roots from the saphenous nerve in the rat. Neurosci Lett, 161:65-8.

16: Lembeck F, Popper H, Juan H (1976): Release of prostaglandins by bradykinin as an intrinsic mechanism of its algesic effect. Naunyn Schmiedebergs Arch Pharmacol, 294:69-73.

17: Kumazawa T, Mizumura K, Koda H, Fukusako H (1996): EP receptor subtypes implicated in the PGE2-induced sensitization of polymodal receptors in response to bradykinin and heat. J Neurophysiol, 75:2361-8.

18: Vergnolle N, Bunnett NW, Sharkey KA, Brussee V, Compton SJ,Grady EF, et al (2001): Proteinase-activated receptor-2 and hyperalgesia: A novel pain pathway. Nat Med, 7:821-6.

19: Ferreira SH, Nakamura M, Salete M (1978): The hyperalgesic effects of prostacyclin and prostaglandin E2. Prostaglandins, 16:31-7.

20: Beiche F, Scheuerer S, Brune K, Geisslinger G, Goppselt-Struebe M (1996): Up-regulation of cyclooxygenase-2 mRNA in the rat spinal cord following peripheral inflammation. FEBS Lett, 22:165-
9.

21: Hay CH, Trevethick MA, Wheeldon A, Bowers JS, De Belleroche JS (1997): The potential role of spinal cord cyclooxygenase- 2 in the development of Freund's complete adjuvant-induced changes in hyperalgesia and allodynia. Neuroscience, 78:84350.

22: Minami T, Nakano H, Kobayashi T, Sugimoto Y, Ushikubi F, Ichikawa A, et al (2001): Characterization of EP receptor subtypes responsible for prostaglandin E2-induced pain re-sponses by use of EP1 and EP3 receptor knockout mice. $\mathrm{Br}$ J Pharmacol, 133:438-44.

23: Samad TA, Moore KA, Sapirrstein A, Billet Sara, Allchorne A, Poole S, et al (2001): In-terleukin1beta-mediated induction of Cox-2 in the CNS contributes to inflammatory pain hypersensitivity. Nature, 410:471-5.

24: Malmberg AB, Hamberger A, Hedner T (1995): Effects of prostaglandin E2 and capsaicin on behavior and cerebrospinal fluid amino acid concentrations of unanesthetized rats: a microdialysis study. J Neurochem, 65:2185-93.

25: Merskey H, Bogduk N (1994): Classification of chronic pain. IASP Press. pp 40-3.

26: Takasaki I, Nojima H, Shiraki K, Sugimoto Y, Ichikawa A, Ushibiki $\mathrm{F}$, et al (2005): In-volvement of cyclooxygenase-2 and EP3 prostaglandin receptor in acute herpetic but not postherpetic pain in mice. Neuropharmacology, 49:283-92.

27: Cunha FQ, Poole S, Lorenzetti BB, Ferreira SH (1992): The pivotal role of tumor necrosis factor alpha in the development of inflammatory hyperalgesia. Br J Pharmacol, 107:660-4.

28: Hori T, Oka T, Hosoi M, Aou S (1998): Pain modulatory actions of cytokines and prosta-glandin E2 in the brain. Ann N Y Acad Sci, 840:269-81. 